\title{
Chemical composition of water buffalo milk and its low-fat symbiotic
}

\section{yogurt development}

\author{
Xue Han ${ }^{1}$, Frank L. Lee ${ }^{2}$, Lanwei Zhang ${ }^{1}$, and M.R. Guo ${ }^{2 *}$ \\ ${ }^{1}$ College of Food Science and Engineering, Harbin Institute of Technology, Harbin, 150090, \\ China; ${ }^{2}$ Department of Nutrition and Food Sciences, 351 Marsh Life Science Building, \\ University of Vermont, Burlington, VT 05405, USA \\ *Corresponding author: Mingruo Guo, Department of Nutrition and Food Sciences, 351 \\ Marsh Life Science Building, University of Vermont, Burlington, VT 05405, USA \\ Submission date: February 13, 2012, Acceptance date: April 17, 2012; Publication date: April \\ 20,2012
}

\begin{abstract}
Background: Water buffalos are the second most widely available milk source in countries around the world. While typical average milk compositions are readily available, information on seasonal variation in chemical composition of buffalo milk is limited -especially in the Northeastern region of the United States. Data collected in this study can be useful for the manufacture of a wide variety of specialty dairy products such as symbiotic buffalo milk yogurt. To analyze functionality, symbiotic low fat buffalo milk yogurt prototypes (plain and blueberry) were developed using a commercial starter containing probiotics.
\end{abstract}

Methods: During a one-year cycle, physicochemical and mineral contents of buffalo milk were analyzed. Prototype yogurts were manufactured commercially and samples of the yogurt prototypes were analyzed for physicochemical and microbiological properties and for the survivability of probiotics during ten weeks of storage.

Results: Average contents of total solids, fat, lactose, crude protein, ash, specific gravity, and conjugated linoleic acid in the milk ranged from $16.39-18.48 \%, 6.57-7.97 \%, 4.49-4.73 \%$, $4.59-5.37 \%, 0.91-0.92 \%, 1.0317-1.0380 \%$, and $4.4-7.6 \mathrm{mg} / \mathrm{g}$ fat, respectively. The average mineral contents of calcium, phosphorous, potassium, magnesium, sodium, and zinc in the milk were $1798.89,1216.76,843.72,337.20$ and $7.48 \mathrm{mg} / \mathrm{kg}$, respectively, and remained steady throughout the year. The symbiotic low fat buffalo milk yogurts evaluated in this study contained higher amounts of protein, carbohydrates, and calcium than similar yogurts manufactured with cows' milk. During refrigerated storage, the probiotic Lactobacillus acidophilus was viable $\left(>1 \times 10^{6} \mathrm{CFU} / \mathrm{g}\right)$ for the first two weeks, while Bifidobacterium spp. 
and Lactobacillus casei remained viable during the entire ten weeks. Reducing the acidity and enhancing the flavor of the yogurts could improve the overall acceptability.

Conclusion: The results indicated that the low fat buffalo milk yogurt are a rich source of nutrients and are nutritionally preferable to cows' milk yogurts. The shelf life analysis indicated it to be a good vehicle for developing symbiotic yogurt.

Keywords: Buffalo milk, conjugated linoleic acid, symbiotic yogurt, probiotic survivability, physicochemical properties, acceptability.

\section{INTRODUCTION:}

World milk production has doubled in the last decade, with water buffalo milk production ranking second after bovine milk [1]. There are two general types of water buffalo, the swamp type (Bubalus carabanesis) and the river type (Bubalus bubalis), which is the most appreciated for milking. The world total buffalo population increase between 1961 and 2001 was $91 \%$ [2], with the major concentration of buffaloes in India (56\% or 94 million animals) followed by China. In North America, before the mid 1970s, there were a few animals in zoos. However, in the last years they have been introduced as an "exotic" livestock hoping to build a market for specialty dairy products [3]. Water buffalo milk in India has a $30 \%$ higher price compared to cows' milk. Buffalo milk is much preferred by consumer for its rich nutrition and is drunk or transformed into valuable products such as cheese, curd, yogurt and ice cream $[4,5]$. Mozzarella manufactured with water buffalo milk is the most highly valued pasta filata cheese in Italy [6] and the United States. Water buffalo milk cheeses in general are becoming increasingly popular throughout the world, and its demand is rising at a rate that is among the highest for any food product [3]. The high demand in specialty dairy products from water buffalo due to its high sensory quality along with the high adaptability of the animals has resulted in making buffaloes part of landscapes unthinkable only a few years ago, for example the Northeast of the United States.

The nutritive interest of water buffalo milk products is also higher than cows' because of the higher concentrations of protein, fat, lactose, minerals and vitamins in buffalo milk [7]. In addition, buffalo milk and its derived products could be a good source of conjugated linoleic acid (CLA) for humans, like other food products from ruminants [8]. CLA refers to a group of polyunsaturated fatty acids (PUFA) that exist as positional and stereoisomers of conjugated dienoeic acid (18:2). The predominant isomer in foods is the cis9, trans11-CLA also called rumenic acid [9] and the trans10, cis12-CLA found primarily in foods containing beef or dairy products [10-12]. Synthetic mixtures of CLA can also be readily purchased as nutritional supplements and are composed primarily of the cis 9 , trans 11 -CLA and trans 10 , cis12-CLA isomers. Numerous potential physiological effects have been attributed to CLA including those related to its potential antiadipogenic, antidiabetogenic, anticarcinogenic, and antiatherosclerotic properties [13]. 
CLA content is much higher in foods derived from ruminants than those from nonruminants, and with milk having higher content than meat, because of the ability of ruminants to biohydrogenate dietary unsaturated fatty acids with the help of bacteria present in the rumen [8]. In dairy products, the CLA concentrations typically range from 2.90 to $8.92 \mathrm{mg}$ CLA/g fat, and the cis9, trans11-CLA isomer makes up between 73-93 percent of the total CLA [14]. CLA content of cheeses typically ranges from 3.59 to $7.96 \mathrm{mg}$ CLA/g fat. CLA content of cows' milk ranges from 3.38 to $6.39 \mathrm{mg}$ CLA/g fat [15]. The amount of CLA found in dairy and beef is a direct reflection of the diet the animals are fed. French et al. [16] found that CLA concentration increases linearly when animals were pasture-fed, and decreases when grass intake declines. CLA content of milk fat can be influenced by manipulating the type of dietary supplement fed to dairy animals. Supplementing the diet with polyunsaturated oils that contain either corn oil or sunflower oil increases CLA content of milk fat substantially [17]. Khanal \& Oslon [8] concluded that the animals diet is the primary factor for enhancing the concentration of CLA in food products such as milk, meat, egg.

Buffalo's milks are used for the manufacture of yogurt and are very popular in countries around the Mediterranean, Middle Eastern countries, southern Russia, and the Indian subcontinent. Buffalo milk contains about twice as much butterfat as cow milk and higher amounts of total solids and casein, making it highly suitable for processing various types of yogurt and resulting in creamy textures and rich flavor profiles.

Yogurt products have been commonly supplemented with probiotics such as Lactobacillus acidophilus (L. acidophilus), Lactobacillus casei (L. casei) and Bifidobacteria to enhance their therapeutic value and to establish a market as a functional food $[18,19]$. The incorporation of probiotic bacteria in various dairy products has become an increasing trend $[20,21]$. Today, yogurt has moved from being a "health food" to being a mainstream "healthy food" that peoples of all ages enjoy. It has been suggested that minimum levels for probiotic bacteria in yogurt is $10^{6}$ viable cells per $\mathrm{mL}$ or $\mathrm{g}$ of product, in order to produce the therapeutic benefits [22-26]. Some researchers stipulate that the viable count of probiotic bacteria should be above $10^{7}$ or $10^{8} \mathrm{CFU} / \mathrm{mL}$ as satisfactory levels [27,28].

However, studies have shown that most probiotic foods have a low population of probiotics and that these organisms are not able to survive during the storage period of yogurts [19]. Many factors may affect the viability of probiotic bacteria in yogurt: acidity, $\mathrm{pH}$, hydrogen peroxide, oxygen content, concentration of organic acid, milk composition and the time and temperature of holding during manufacture, transport and storage of yogurt $[21,25,29,30]$. Therefore, it is important to ensure adequate and viable probiotic bacteria throughout the shelf life of yogurt products.

Similar to the differences in cows' milk, changes in buffalo milk composition due to breed, geographical location, and feeding; and these variations would strongly affect the manufacturing conditions, sensory quality, and nutritional properties of yogurt products. Currently, information on chemical composition including CLA content in water buffalo milk, and the survivability of probiotics in low-fat buffalo yogurts during refrigerated storage 
throughout the year in the northeast U.S. is limited. Therefore, the objectives of this study were to investigate the seasonal changes in physicochemical composition and CLA content of bulk-collected water buffalo milk over one year and using buffalo milk from the same herd to produce a low fat buffalo yogurt. The gross composition, including mineral composition, fatty acid analysis, and survivability of several common probiotics in this symbiotic yogurt, were also evaluated to provide valuable data regarding buffalo yogurt.

\section{MATERIALS AND METHODS:}

Collection of milk samples: Bulk milk samples were collected monthly at the second week from a commercial water buffalo dairy farm and producer (Woodstock Buffalo yogurt company (now Bufala di Vermont) Woodstock, Vt., U.S.A.) for the duration of one year. The breeds of the water buffalos were mostly Riverine, with a mix of Murrah, Nili-Rivi and Jafrabadi, and their diet included a mixture of corn silage, baylage and palletized supplements. The samples, approximately 4-6 kg, were placed directly into an ice chest and transported to the Analytical Foods Laboratory at the University of Vermont. The buffalo milk samples were stored at $4^{\circ} \mathrm{C}$ until portions were analyzed the following day. Prior to analysis of fatty acid content, buffalo milk samples were stored at $-70^{\circ} \mathrm{C}$.

Compositional analysis: Milk samples were analyzed for chemical composition using standard AOAC procedures [31]. Minerals were determined using Inductively Coupled Plasma Atomic Emission Spectroscopy (ICPAES, Leeman Labs Plasma Spec Z.5, Lowel, MA) [32]. All values reported are the mean of three measurements. Milk sample pH was measured directly with a combination electrode according to Bradley [33].

CLA analysis: Tridecanoate (13:0), a mixture of 19 fatty acid methyl esters (FAME), a mixture of CLA isomers (free fatty acids; 80\% cis9, trans11-18:2, 17\% cis9, cis11-18:2, and 1\% trans9, trans11-18:2) were purchased from Matreya (Pleasant Gap, PA). Sodium methoxide in methanol $(0.5 \mathrm{~N})$ and methyl acetate were obtained from Sigma-Aldrich Co. (St. Louis, MO). An analytical nitrogen evaporator (19 gauge, 4" long, blunt end) was purchase from Organomation Associates, Inc (Berlin, MA). All chemicals and reagents used were of analytical grade.

Lipid extraction: Lipids were extracted in duplicates according to the Mojonnier procedure. Briefly, $10 \mathrm{~g}$ ( $10 \mathrm{~g} \mathrm{x}$ 2) of the milk sample was measured into the Mojonnier flask, $1.5 \mathrm{~mL}$ ammonium hydroxide $\left(\mathrm{NH}_{4} \mathrm{OH}\right)$ was added and thoroughly mixed. Three drops of $1 \%$ phenolpthalein indicator (w/v in ethyl alcohol) was added to visualize the appearance of interface between the extractant and the aqueous layer. Ten $\mathrm{mL}$ of $95 \%$ alcohol was added to the flask and shaken vigorously for $1 \mathrm{~min}, 25 \mathrm{~mL}$ diethyl ether was added and shaken for another $1 \mathrm{~min}$. Finally, $25 \mathrm{~mL}$ petroleum ether was added and after shaking for $1 \mathrm{~min}$ the organic layer was carefully decanted. This procedure was repeated one more time by adding 5 
$\mathrm{mL} \mathrm{95 \%} \mathrm{alcohol,} 15 \mathrm{~mL}$ diethyl ether, and $15 \mathrm{~mL}$ petroleum ether. The solvent was evaporated under nitrogen at $40{ }^{\circ} \mathrm{C}$ and the lipid samples were dried under nitrogen and weighed.

Methylation of lipid: Lipid samples were methylated using the method described by Christie (34) modified by Shahin et al (35). Briefly, $4 \mathrm{mg}$ of the lipid was dried under nitrogen, diethyl ether $(1 \mathrm{~mL})$ was added, followed by $20 \mu \mathrm{L}$ methyl acetate and $40 \mu \mathrm{L}$ of $0.5 \mathrm{~N}$ $\mathrm{NaOCH}_{3}$. The reaction mixture was vortexed to ensure complete mixing. After $10 \mathrm{~min}$ at room temperature, the reaction was stopped by adding $30 \mu \mathrm{L}$ saturated oxalic acid prepared in diethyl ether. The mixture was centrifuged at $2400 \mathrm{X}$ g at $4{ }^{\circ} \mathrm{C}$ and dried under a gentle stream of nitrogen. Hexane $(1 \mathrm{~mL})$ was added, and the mixture was passed through a Pasteur pipette column containing a glass wool plug and a $4 \mathrm{~cm}$ silica gel overlaid with $1 \mathrm{~cm}$ anhydrous $\mathrm{MgSO}_{4}$. Samples were concentrated under nitrogen to $100 \mu \mathrm{L}$ and transferred into a gas liquid chromatographic vial. Tridecanoate (13:0) was added as an internal standard after the lipid extraction to quantify the fatty acid methyl ester concentration.

Fatty acid methyl ester (FAME) analysis: FAME were analyzed manually by a gas chromatograph (Shimadzu, GC 17-A) with a flame ionization detector using a SP-2560 capillary column (100 m x 0.25 mm id., $0.2 \mu \mathrm{m}$ film thickness; Supelco, Inc. Bellefonte, PA). The analysis involved a programmed run with temperature ramps under conditions and temperatures described by Shahin et al (35). Fatty acid profiles were determined by split injection (100:1) and nitrogen as carrier gas. Identity of the fatty acid methyl ester was established by comparing retention times to a CLA mixture containing $80 \%$ cis 9 , trans 11 18:2; $17 \%$ cis 9 , cis11-18:2 and 1\% trans9, trans $11-18: 2$.

Yogurt samples: The Woodstock Buffalo Company produced the prototype buffalo yogurts following methods provided by the researchers.

Prototype plain and blueberry flavored low-fat buffalo yogurt samples were obtained from the same producer and stored at $4^{\circ} \mathrm{C}$ for ten weeks. The counts of probiotic bacteria were evaluated each week over ten week storage at $4^{\circ} \mathrm{C}$. The values of $\mathrm{pH}$, titratable acid, viscosity and yeast and mold counts were also determined each week.

Compositional and pH analysis of yogurt: Total solids (TS) of the yogurt samples were measured by forced-draft oven at $105^{\circ} \mathrm{C}$ until a steady weight was achieved (approximately $24 \mathrm{~h}$ ). Ash was measured gravimetrically and fat contents were measured by the Babcock standard, both methods according to procedures of the standard methods for the examination of Dairy Products [36]. Protein content was analyzed using standard AOAC procedures (37). Carbohydrate content was determined by difference. The $\mathrm{pH}$ values of yogurt samples were measured using $\mathrm{pH}$ meter and ATC probe combination (model IQ 240, IQ Scientific Instruments Inc., San Diego, Calif., U.S.A.). 
Mineral analysis of yogurt: For determination of mineral concentrations, yogurt samples $(10 \mathrm{~g})$ were dry-ashed in porcelain crucibles at $550^{\circ} \mathrm{C}$ for $6 \mathrm{~h}$, solubilized with $10 \mathrm{ml}$ of $6 \mathrm{M}$ $\mathrm{HCl}$, quantitatively transferred into $25 \mathrm{ml}$ volumetric flasks, and diluted to volume with double-deionized water, according to standard AOAC protocol (37). Calcium (Ca), zinc ( $\mathrm{Zn})$, sodium $(\mathrm{Na})$ and magnesium $(\mathrm{Mg})$ contents were determined utilizing Inductively Coupled Plasma Atomic Emission Spectroscopy (ICPAES, Leeman Labs Plasma Spec Z.5, Lowel, Mass., U.S.A.) (38,39). Values reported are the averages of 3 measurements \pm standard deviations.

Viscosity measurement of yogurt: Viscosity measurements were carried out at ambient temperatures $\left(22 \pm 2^{\circ} \mathrm{C}\right)$ using a Brookfield Programmable DV-II+ viscometer (Brookfield Engineering Laboratories, Inc., Middleboro, Mass., U.S.A.) equipped with a No. 4 spindle at $20 \mathrm{rpm}$. Values were taken at $30 \mathrm{~s}$ interval and each yogurt sample size was approximately $300 \mathrm{~g}$.

Enumeration of probiotic bacteria in yogurt: Yogurt samples were withdrawn on a weekly basis for $10 \mathrm{wk}$ to inquire how long the probiotics can survive in the product. Enumeration procedures were adapted from methods based on International standard ISO 20128 / IDF 192 (40) The colonies of each probiotic had a different morphology, which was used to enumerate each probiotic separately. L. acidophilus was quantified with MRS-IM agar with maltose using spread plate method, followed by $72 \mathrm{~h}$ incubation at $37^{\circ} \mathrm{C}$ under aerobic conditions. $L$. acidophilus formed flat, mat, rough, grey/white colonies with irregular edges and a diameter of $1 \mathrm{~mm}-3 \mathrm{~mm}$. Bifidobacterium were enumerated using the pour plate method with MRS-IM agar and glucose containing $0.05 \%$ dichloxacillin, $0.1 \%$ lithium chloride and $0.05 \%$ cysteine hydrochloride, followed by $72 \mathrm{~h}$ incubation at $37^{\circ} \mathrm{C}$ under anaerobic conditions. Bifidobacterium colonies appeared as large, white colonies that are club or bone shaped. $L$. casei was determined with MRS-IM agar and glucose using the spread plate method, followed by $6 \mathrm{~d}$ incubation at $20^{\circ} \mathrm{C}$ under aerobic conditions. The white-colored colonies of $L$. casei were flat and irregular in shape, with wavy edges. The enumeration of probiotics, performed in triplicate, were calculated from the colonies on agar plates and thus expressed as colony forming units per gram (CFU/g).

Yeast and mold counts: Yogurt samples were screened weekly using Yeast and Mold Petrifilm $^{\mathrm{TM}}$ (3M Petrifilm ${ }^{\mathrm{TM}}$, St. Paul, Minn., U.S.A.) incubated at $23^{\circ} \mathrm{C}$.

Consumer acceptability: Commercial plain and blueberry-flavored cows' milk yogurt with similar fat contents were purchased for comparison with the water buffalo milk yogurt samples. The consumer group was constituted by a sample of subjects ( $n=104$ for the plain and $n=97$ for the blueberry) enlisted at a local natural foods market. For each flavor evaluated, the yogurt samples were randomly presented using 3-digit codes and convenient sampling. Face-to-face interviews were also conducted. During the survey, consumers were 
asked to express their preference about the yogurt samples evaluated and rate the acceptability of the product for different sensory properties using an increasing intensity 9-pt scale, with a score of 1 to "dislike extremely" and 9 to "like extremely" with additional openended questions in terms of product preference.

Statistical analysis: Data were analyzed using OriginPro 7.5 (OriginLab Corporation, Northampton, Mass., U.S.A.). Each yogurt type was analyzed on three different occasions and each trial of samples was performed in triplicates. Consumer acceptance data were statistically analyzed by paired t-tests, ANOVA and Chi-square tests. A P $<0.05$ was regarded as significant.

\section{RESULTS AND DISCUSSION:}

Composition and nutrient profile of milk: The means, with standard deviations, of $\mathrm{pH}$ and chemical composition of buffalo milk are shown in Table 1.

Table 1. Gross composition of water buffalo milk during this study ${ }^{\mathrm{a}}$. All values reported are the mean of three measurements The samples were taken from a monthly bulk sample and analyzed the day after production.

\begin{tabular}{llrllll}
\hline Months & pH & $\begin{array}{r}\text { Total solids } \\
(\%)\end{array}$ & Fat $(\%)$ & $\begin{array}{l}\text { Crude } \\
\text { Protein }(\%)\end{array}$ & Lactose(\%) & Ash (\%) \\
\hline January & $6.79 \pm 0.01$ & $18.45 \pm 0.04$ & $7.63 \pm 0.03$ & $5.37 \pm 0.11$ & $4.50 \pm 0.08$ & $0.92 \pm 0.01$ \\
February & $6.76 \pm 0.01$ & $18.20 \pm 0.09$ & $6.58 \pm 0.03$ & $5.23 \pm 0.03$ & $4.73 \pm 0.04$ & $0.92 \pm 0.03$ \\
March & $6.82 \pm 0.01$ & $18.48 \pm 0.03$ & $7.07 \pm 0.06$ & $5.25 \pm 0.02$ & $4.59 \pm 0.10$ & $0.92 \pm 0.01$ \\
April & $6.98 \pm 0.01$ & $16.39 \pm 0.01$ & $6.68 \pm 0.03$ & $4.65 \pm 0.04$ & $4.49 \pm 0.06$ & $0.91 \pm 0.05$ \\
May & $6.88 \pm 0.01$ & $17.51 \pm 0.03$ & $6.90 \pm 0.01$ & $5.12 \pm 0.06$ & $4.56 \pm 0.03$ & $0.91 \pm 0.02$ \\
June & $6.85 \pm 0.01$ & $16.61 \pm 0.02$ & $6.80 \pm 0.01$ & $4.59 \pm 0.37$ & $4.50 \pm 0.07$ & $0.91 \pm 0.03$ \\
July & $6.82 \pm 0.01$ & $17.29 \pm 0.08$ & $6.57 \pm 0.06$ & $4.70 \pm 0.09$ & $4.60 \pm 0.08$ & $0.92 \pm 0.01$ \\
August & $6.89 \pm 0.01$ & $17.78 \pm 0.01$ & $7.02 \pm 0.03$ & $5.14 \pm 0.10$ & $4.49 \pm 0.02$ & $0.92 \pm 0.04$ \\
September & $6.91 \pm 0.01$ & $17.79 \pm 0.01$ & $7.40 \pm 0.01$ & $5.11 \pm 0.13$ & $4.55 \pm 0.04$ & $0.92 \pm 0.03$ \\
October & $6.91 \pm 0.01$ & $17.98 \pm 0.02$ & $7.60 \pm 0.01$ & $5.10 \pm 0.07$ & $4.66 \pm 0.06$ & $0.92 \pm 0.01$ \\
November & $6.78 \pm 0.03$ & $18.47 \pm 0.01$ & $7.97 \pm 0.06$ & $4.98 \pm 0.26$ & $4.69 \pm 0.01$ & $0.92 \pm 0.02$ \\
December & $6.83 \pm 0.03$ & $18.40 \pm 0.03$ & $7.37 \pm 0.06$ & $4.94 \pm 0.02$ & $4.70 \pm 0.03$ & $0.92 \pm 0.05$ \\
\hline
\end{tabular}

${ }^{\mathrm{a}}$ Values represent Mean $\pm \mathrm{sd} ; \mathrm{n}=3$.

Range values throughout the twelve month study period for $\mathrm{pH}(6.76-6.98)$, total solids 
$(16.39-18.47 \%)$, and ash $(0.91-0.92 \%)$ were within normal range with data reported in the United Kingdom, and by Ligda et al (3), fat $(6.57-7.97 \%)$, crude protein $(4.59-5.37 \%)$ and lactose $(4.49-4.73 \%)$ was also within the ranges determined from global milk production analysis by Barlowska et al [41]. However, these values varied during the twelve months and between seasons. Content of total solids was higher in the months of November through March as compared to April through October. Fat content was higher in the months of September through January as compared to February through August. Concentration of crude protein was higher from November through May as compared to June through October. Table 1 also shows that water buffalo milk contains more than $16 \%$ total solids compared with 12$14 \%$ for cows' milk. In addition, fat content is shown to be at least $50 \%$ higher $(6-8 \%)$ than cows' milk (3-5\%) [32,41]. This is comparable to results from a study of 7,770 Nili/Ravi buffalos in herds at the Pakistan Research Institute which showed an average fat content of $6.4 \%$ (a mean based on 10 tests over 10 months) for buffalo milk. Of all the milk samples they analyzed, $77 \%$ ranged between 5 and $8 \%$ fat and $12 \%$ were below the $5 \%$ fat content [3]

The means, with standard deviations, of mineral content in buffalo milk are shown in Table 2. Range values $(\mathrm{mg} / \mathrm{kg})$ throughout the twelve-month study period are; for $\mathrm{Ca}(1021.9$ - 2059.4), P (706.7 - 1513.0), K (468.1 - 984.1), Na (235.0 - 461.5), Mg (89.7 - 201.6) and $\mathrm{Zn}(3.8$ - 16.3) all of which being within the normal global averages for buffalo milk [41]. Mineral contents of water buffalo milk are similar to that of cows' milk except for calcium and phosphorus, which occurs approximately twice the amount in water buffalo milk.

Table 2. Mineral composition ( $\mathrm{mg} / \mathrm{kg}$ ) of water buffalo milk during this study ${ }^{\mathrm{a}}$. The samples were taken from a monthly bulk sample and analyzed the day after production. All values reported are the mean of three measurements

\begin{tabular}{lcccccc}
\hline Month & Calcium & Phosphorus & Potassium & Sodium & Magnesium & Zinc \\
\hline January & $1693.7 \pm 9.2$ & $1217.0 \pm 4.6$ & $834.7 \pm 8.0$ & $419.4 \pm 4.0$ & $150.1 \pm 0.4$ & $7.4 \pm 0.3$ \\
February & $1834.5 \pm 17.4$ & $1307.0 \pm 14.1$ & $890.3 \pm 13.3$ & $418.4 \pm 5.9$ & $182.5 \pm 1.6$ & $10.0 \pm 0.8$ \\
March & $1505.1 \pm 5.1$ & $1033.6 \pm 9.2$ & $721.4 \pm 6.8$ & $350.1 \pm 1.1$ & $128.2 \pm 1.8$ & $7.5 \pm 0.2$ \\
April & $1021.9 \pm 14.1$ & $706.7 \pm 16.7$ & $468.1 \pm 9.8$ & $245.3 \pm 3.8$ & $89.7 \pm 1.4$ & $3.8 \pm 0.2$ \\
May & $2010.1 \pm 35.1$ & $1393.4 \pm 33.1$ & $984.1 \pm 18.3$ & $383.8 \pm 6.0$ & $172.1 \pm 3.3$ & $8.6 \pm 0.6$ \\
June & $16.71 .2 \pm 11.3$ & $1215.0 \pm 14.0$ & $759.3 \pm 4.9$ & $267.2 \pm 0.9$ & $135.4 \pm 0.9$ & $16.3 \pm 3.7$ \\
July & $2034.4 \pm 7.6$ & $1317.0 \pm 3.8$ & $947.0 \pm 6.6$ & $295.6 \pm 0.5$ & $145.5 \pm 0.7$ & $6.3 \pm 0.1$ \\
August & $2059.4 \pm 9.4$ & $1242.7 \pm 3.1$ & $920.3 \pm 6.2$ & $235.0 \pm 1.4$ & $137.1 \pm 1.4$ & $5.4 \pm 0.2$ \\
& & & & & & \\
\hline
\end{tabular}


September $1983.6 \pm 19.6 \quad 1241.7 \pm 28.9 \quad 850.8 \pm 33.8$

$260.8 \pm 12.5 \quad 142.7 \pm 2.6 \quad 7.0 \pm 2.1$

October $\quad 1973.6 \pm 20.8 \quad 1136.3 \pm 8.4 \quad 853.7 \pm 17.7 \quad 295.0 \pm 12.4 \quad 146.1 \pm 1.4 \quad 5.4 \pm 0.1$

November $\quad 1891.8 \pm 19.4 \quad 1115.2 \pm 24.8 \quad 785.4 \pm 22.5 \quad 300.5 \pm 17.1 \quad 154.7 \pm 4.7 \quad 5.8 \pm 0.3$

December $\quad 1747.0 \pm 27.9 \quad 1513.0 \pm 130.6 \quad 954.1 \pm 31.2 \quad 461.5 \pm 15.2 \quad 201.6 \pm 6.9 \quad 8.1 \pm 0.8$

${ }^{\mathrm{a}}$ Values represent Mean $\pm \mathrm{sd} ; \mathrm{n}=3$.

Table 3 represents the major fatty acid esters including the cis9, trans11-CLA isomer analyzed by gas chromatographic technique. The major saturated fatty acid was palmitic (16:0) followed by stearic (18:0) and myristic (14:0). A similar result for these fatty acids has been reported previously by Bergamo [42] in water buffalo milk. The concentration of these fatty acids varied during the year.

Table 3. Fatty Acid (FA) Composition (mg/g fat) of water buffalo milk during the study ${ }^{\mathrm{a}}$. The samples were taken from a monthly bulk sample and held at $-70{ }^{\circ} \mathrm{C}$ before analysis. All values reported are the mean of three measurements

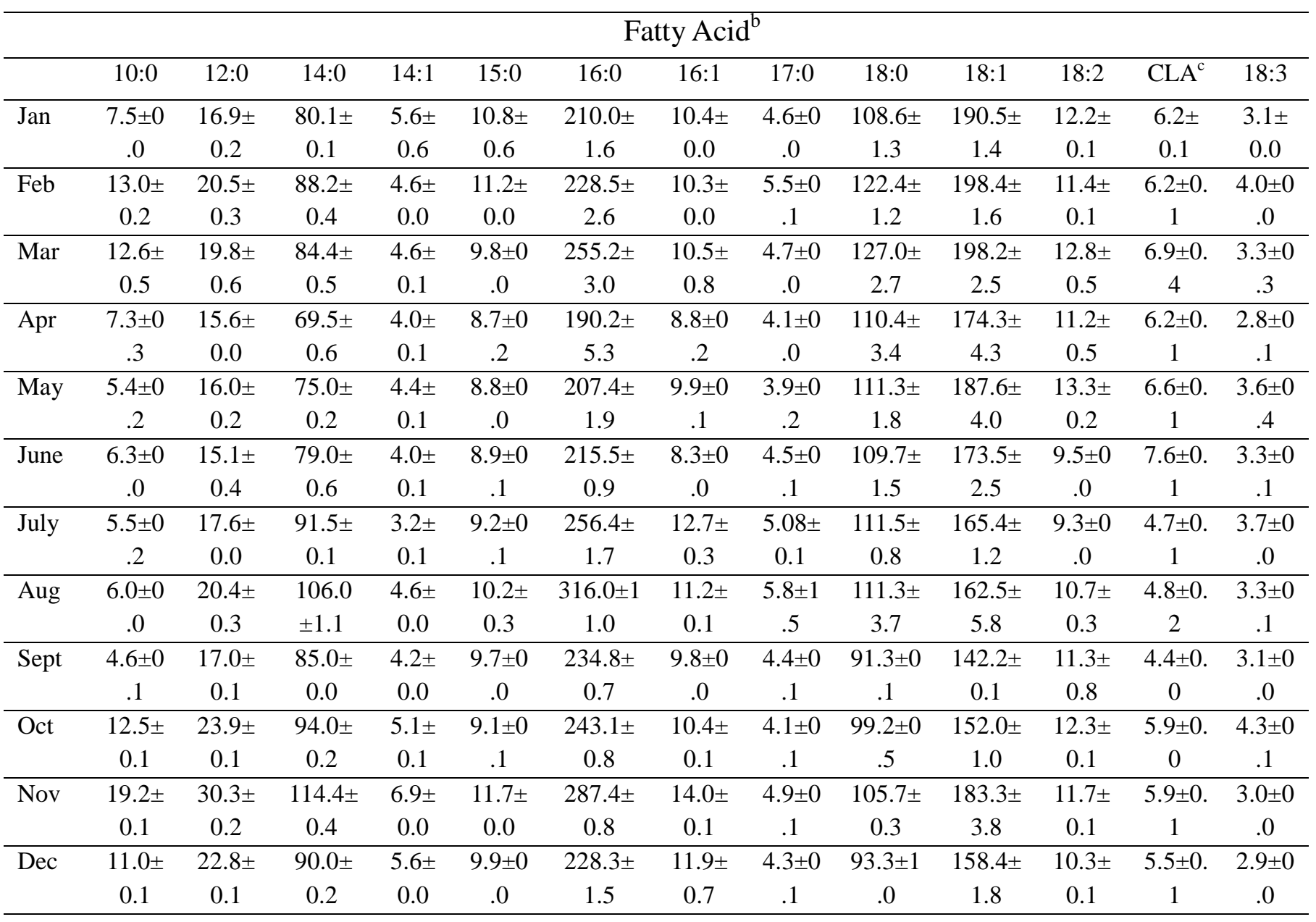


${ }^{\mathrm{a}}$ Values represent mean $\pm \mathrm{s.d} ; \mathrm{n}=2 ;{ }^{\mathrm{b}}$ Capric acid, 10:0; lauric acid, 12:0; myristic acid, 14:0; myristoleic, 14:1; pentadecanoic acid, 15:0; palmitic acid, 16:0; palmitoleic acid, 16:1; margaric acid, 17:0; stearic acid, 18:0; oleic acid, 18:1; linoleic acid, 18:2, CLA, 18:2 and linolenic acid, 18:3. ${ }^{\mathrm{c}}$ Conjugated linoleic acid (cis9, trans11-CLA isomer).

Much interest has been taken in the components of milk fats which are thought to have benefits for human health, these include conjugated linoleic acids (CLA) found in milk fats. The average cis9, trans11-CLA content (the principal CLA in milk fats) during analysis was $5.91 \pm 0.93$ (mg/g fat) and varies between $4.4 \pm 0.0$ to $7.6 \pm 0.4$ respectively. In comparison, Bergamo [42] reported $7.3 \pm 0.8$ (mg/g fat) of cis9, trans11-CLA in conventional buffalo milk. The CLA content of Asian water buffalo milk is around $8.0 \mathrm{mg} / \mathrm{g}$ fat [43]. In the present study, the cis9, trans-11CLA concentration was found to be lower (average $4.6 \mathrm{mg} / \mathrm{g}$ fat) during the month of July, August and September. However, variation in CLA concentration of milk occurs due to a number of factors including season [44]. To minimize the effect of seasonal variations on buffalo milk fat composition, Bergamo [42] collected milk samples during a 3 month period (from April to June).

Gross composition of yogurt: Gross composition and mineral contents of the buffalo milk yogurt are listed in Tables 4 and 5, respectively.

Table 4. Gross composition of low fat buffalo milk yogurt (mean \pm SD, $n=9)$

\begin{tabular}{lccccc}
\hline Flavor & Protein $(\%)$ & Fat $(\%)$ & TS $(\%)$ & Ash $(\%)$ & CHO (\%) \\
\hline Plain & $4.49 \pm 0.31$ & $0.68 \pm 0.03$ & $11.60 \pm 0.58$ & $0.82 \pm 0.06$ & $5.68 \pm 0.18$ \\
Blueberry & $4.16 \pm 0.11$ & $0.55 \pm 0.05$ & $17.12 \pm 0.36$ & $0.78 \pm 0.02$ & $11.38 \pm 0.18$ \\
\hline
\end{tabular}

Table 5. Mineral contents (mg/g) of low fat buffalo milk yogurt (mean $\pm \mathrm{SD}, \mathrm{n}=9$ )

\begin{tabular}{lllll}
\hline Flavor & $\mathrm{Ca}^{2+}$ & $\mathrm{Mg}^{2+}$ & $\mathrm{Zn}^{2+}$ & $\mathrm{Na}^{+}$ \\
\hline Plain & $1.97 \pm 0.20$ & $1.63 \pm 0.02$ & $0.07 \pm 0.01$ & $0.87 \pm 0.15$ \\
Blueberry & $1.72 \pm 0.06$ & $1.69 \pm 0.01$ & $0.07 \pm 0.00$ & $0.94 \pm 0.12$ \\
\hline
\end{tabular}

Buffalo milk yogurt showed higher contents of protein, TS, carbohydrate, and ash than those reported for cow milk yogurt. [45,46], indicating higher nutrient density in buffalo milk yogurt. The average protein $(4.49 \pm 0.31$ and $4.16 \pm 0.11 \%)$ and ash $(0.82 \pm 0.06$ and $0.78 \pm$ $0.02 \%$ ) for plain and blueberry flavor yogurt respectively were within the normal range for 
buffalo milk composition [41]. The fat in plain and blueberry buffalo yogurt were $0.68 \pm$ $0.03 \%$ and $0.55 \pm 0.05 \%(\mathrm{w} / \mathrm{w})$ respectively. These verified these two kinds of buffalo yogurts belong to the low fat yogurt, for the low fat milk or yogurt; the fat content should below the $2 \%$. The TS of plain flavor buffalo milk yogurt was $11.60 \pm 0.58 \%$, which was lower than that of buffalo milk (18.44\%), because most fat in buffalo milk was removed (the average fat content of buffalo milk was $7.13 \%$ Table 1 . However, the TS in blueberry yogurt $(17.12 \% \pm 0.36 \%)$ were higher than that in plain yogurt $(11.60 \% \pm 0.58 \%)$. In terms of important minerals; calcium was $1.97 \pm 0.20$ and $1.72 \pm 0.06 \mathrm{mg} / \mathrm{g}$ for plain and blueberry yogurt respectively and it was superior to cow milk $(1.2 \mathrm{mg} / \mathrm{g})[47]$ and sheep milk $(1.5 \mathrm{mg} / \mathrm{g})$ [32]. Gross composition of buffalo yogurt varies depending on the type of raw materials used, type of yogurt manufactured and fortification methods, etc. [25].

Viscosity changes during storage: Figure 1 (a) represents the changes in viscosity during 10 week storage. The yogurt had a viscosity between 1.78 and 1.40 Pa.s for plain flavor and 2.15 and 1.61 Pa.s for blueberry flavor. Analysis of variance showed that there was no significant change in viscosity during storage for 10 weeks $(\mathrm{p}<0.05)$. However the viscosity of blueberry flavor yogurt was higher than that of the plain flavor because the blueberry flavor yogurt has higher levels of carbohydrate and total solids (Table 4). This may have improved the yogurt gel stability. Similar results have also been reported by Farnsworth et al [25] in production of goats milk yogurt showing that increasing total solids of the goat milk can improve yogurt viscosity.

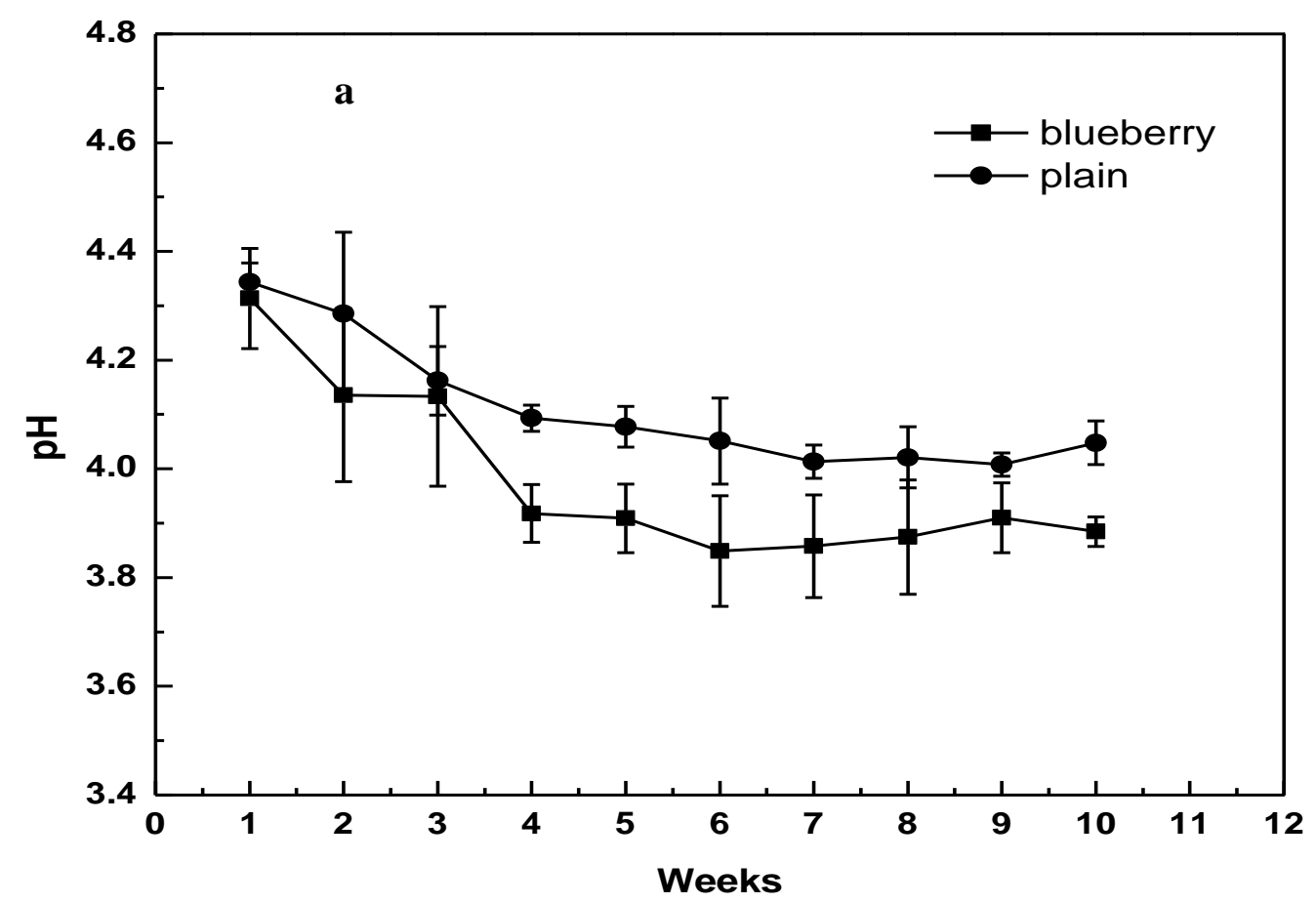



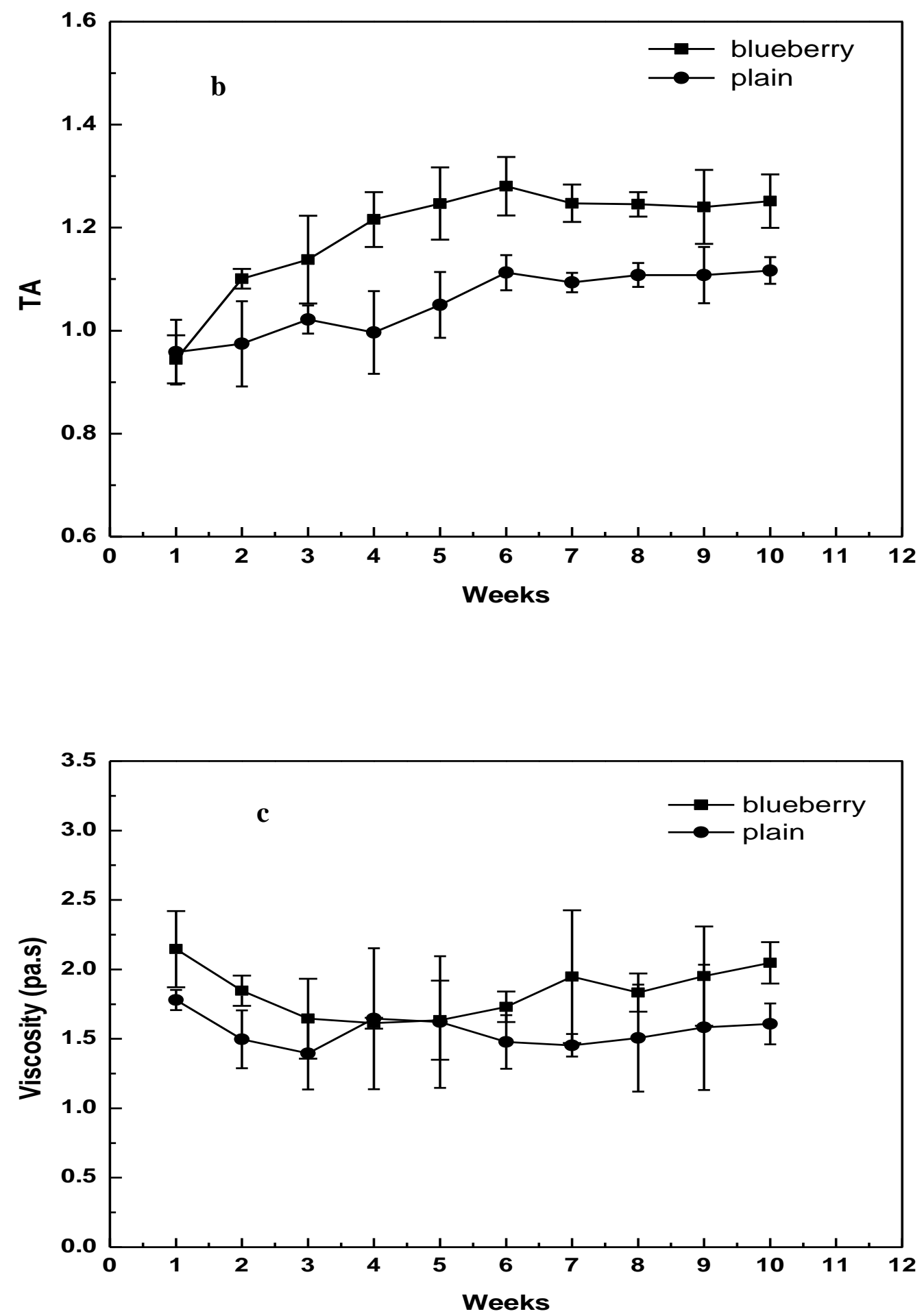

Figure 1. Changes in $\mathrm{pH}(\mathrm{a})$, titratable acidity (b) and viscosity (c) of blueberry flavoured ( $\mathbf{})$ and plain $(\bullet)$ low fat buffalo milk yogurt during storage.

Changes in pH and titratable acidity during storage: Figure 1(b, c) represents the changes in $\mathrm{pH}$ and titratable acidity of yogurt during storage. The initial (1st week) $\mathrm{pH}$ was 4.34 and 4.31, and the final (10th week) $\mathrm{pH}$ was 4.05 and 3.89 for plain and blueberry yogurt 
respectively. Analysis of variance showed that there was a significant difference $(p<0.05)$ between the $\mathrm{pH}$ at week 1 and week 10 across the two types of stored yogurts. The $\mathrm{pH}$ of the two types of yogurt significantly decreased from 1 to 6 week's storage and then stabilized with no further significant change up to 10 weeks of storage. Shah [48] observed similar decreases in $\mathrm{pH}$ values during storage of commercial yogurts containing L. acidophilus and $B$. bifidum. The decline in $\mathrm{pH}$ was presumably due to continued fermentation by the lactic acid bacteria during storage $[48,49]$.

The initial $\mathrm{pH}$ of the plain and blueberry yogurt was approximately the same $\mathrm{pH}$ about 4.3), however, the blueberry yogurt showed the lower $\mathrm{pH}$ at the end of 10 week shelf-life (Figure $1 b)(p>0.05)$. It is possible that addition of the blueberry into yogurt may have decreased $\mathrm{pH}$ during storage [21].

The titratable acidity change trend was similar with that of $\mathrm{pH}$ during storage The titratable acidity was increased a little with storage time, and it peaked at 6 weeks storage. At 6 weeks storage the titratable acidity of plain and blueberry flavor were $1.11 \%$ and $1.28 \%$ respectively, but there were no significant differences in TA between 6 and 10 weeks.

Survivability of probiotic bacteria during storage: Figure 2 shows the survivability of $L$. acidophilus, Bifidobacterium and L. casei for 10 weeks in refrigerated condition.

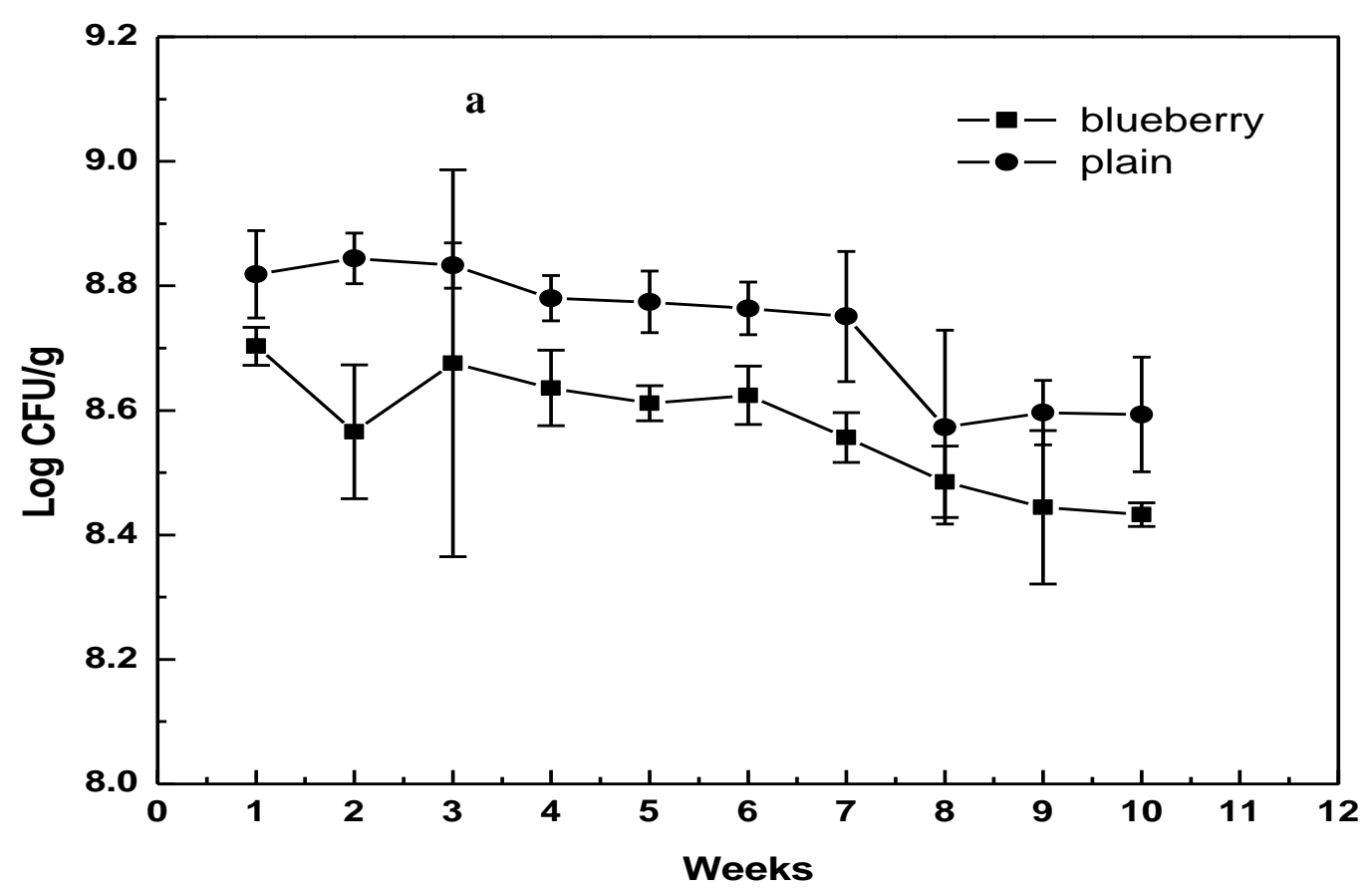



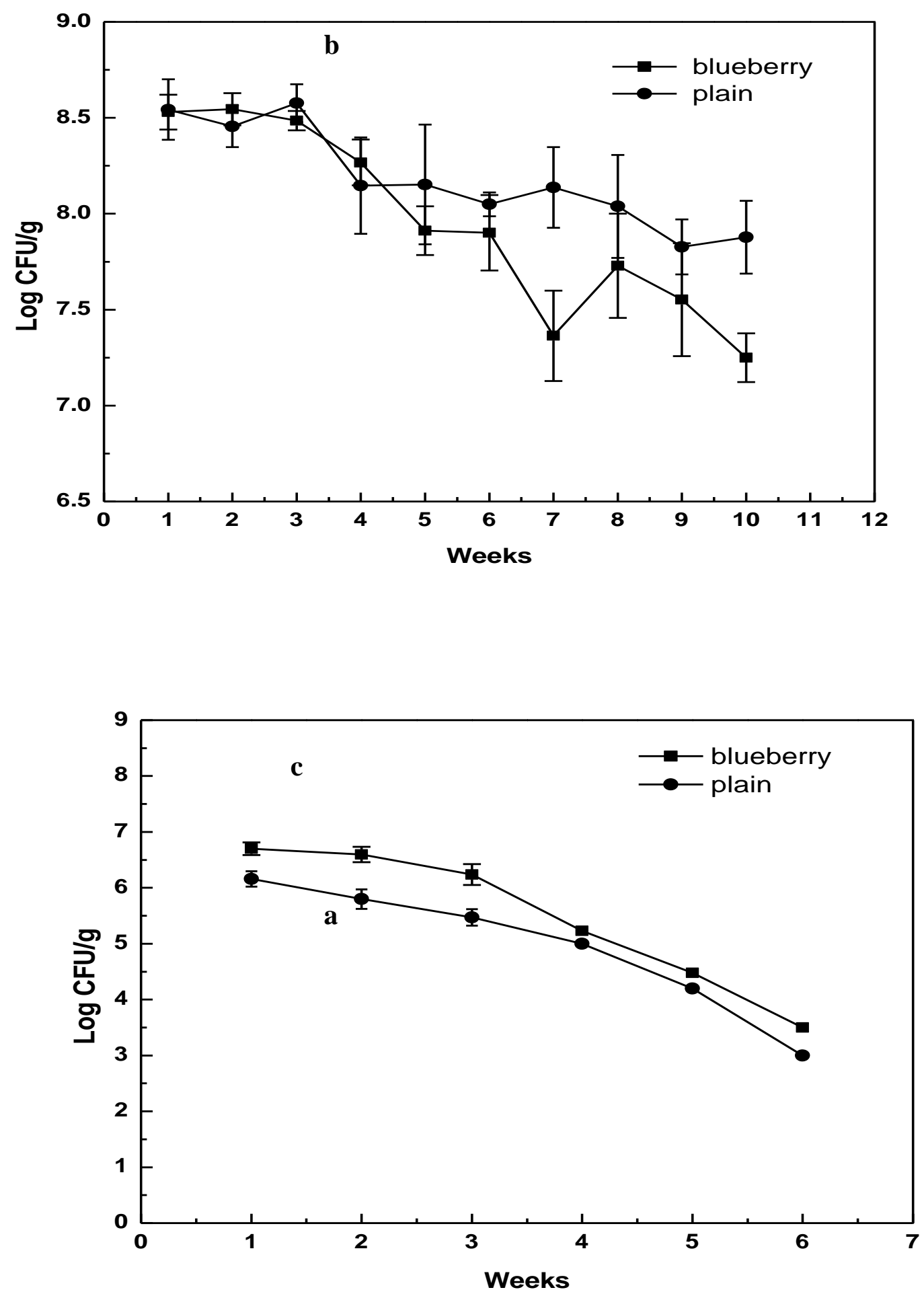

Figure 2. Survivability of Bifidobacterium (a), Lactobacillus casei (b) and L. acidophilus (c) in low fat buffalo milk yogurt during storage. *There were no significant different for Bifidobacterium during seven week storage ( $\mathrm{p}>0.05$ ). For Lactobacillus casei there were significant different after four week storage, and for L. acidophilus after three week storage $(\mathrm{p}<0.05)$ 
Analysis of variance for the probiotic counts showed that there was no significant change in Bifidobacterium and L. casei populations during 4 week storage ( $>>0.05)$, whereas, with $L$. acidophilus, there was significant change after the 3rd week $(\mathrm{p}<0.05)$ (Figure $2 \mathrm{c})$. The population of Bifidobacterium ranged from $6.58 \times 10^{8}$ to $2.78 \times 10^{8} \mathrm{CFU} / \mathrm{g}$ and $5.05 \times 10^{8}$ to $2.52 \times 10^{8} \mathrm{CFU} / \mathrm{g}$ for plain and blueberry flavor yogurt respectively over 10 weeks storage. The population of L. casei ranged from $3.49 \times 10^{8}$ to $6.90 \times 10^{7} \mathrm{CFU} / \mathrm{g}$ and $3.39 \times 10^{8}$ to 1.42 $\times 10^{7} \mathrm{CFU} / \mathrm{g}$ for plain and blueberry flavor yogurt respectively during the 10 week storage. But the population of L. acidophilus was $1.44 \times 10^{6}$ and $5.01 \times 10^{6} \mathrm{CFU} / \mathrm{g}$ for plain and blueberry flavor yogurt respectively at the beginning of storage ( $1^{\text {st }}$ week). At the 3 rd week, it was only $1.00 \times 10^{5}$ and $1.70 \times 10^{5} \mathrm{CFU} / \mathrm{g}$ for plain and blueberry yogurt respectively. Similar results were found by Dave and Shah [23], they reported that the survival of $L$. acidophilus in cow milk yogurts after $35 \mathrm{~d}$ of storage was only approximately $0.1 \%$ to $5 \%$ compared to after $5 \mathrm{~d}$ of storage. Shah [50] found different brands of cow milk yogurt contained different quantities of viable cells of $L$. acidophilus and Olson [51] also reported that there is a wide range of survival of L. acidophilus in cow milk yogurt.

Among the 3 cultures, L. acidophilus differed significantly in survivability from the other 2 probiotics. The results of the present study indicated that the low fat buffalo yogurt may be a good carrier for developing probiotic yogurt containing Bifidobacterium and $L$. casei.

In addition, the survivability of bifidobacterium and $L$. casei in the plain were higher than in the blueberry yogurt during storage. The survivability of L. acidophilus in the plain flavor, however, was lower than that in the blueberry yogurt. Similar results were also reported by Kailasapathy [21] for cow milk yogurts, indicating blueberry juice had a negative impact on the viability of some probiotics. Furthermore blueberry can add good flavor to the yogurt.

Detection of mold and yeast: The presence of mold and yeast in yogurts has a substantial bearing on organoleptic properties and shelf life of the product. The counts of mold and yeast in the low-fat buffalo yogurt during refrigerated storage are shown in Table 6. After seven weeks of refrigerated storage, yeast was detected in plain yogurt, while in blueberry yogurt is eight week and with prolonged storage time, mold was also found. Therefore the shelf-life of low fat buffalo yogurt should be less than eight weeks.

Table 6. Counts of mold and yeast in low fat buffalo milk yogurt during storage*

\begin{tabular}{lllll}
\hline \multirow{2}{*}{ Week } & \multicolumn{2}{l}{ Plain $(\mathrm{CFU} / \mathrm{mL})$} & \multicolumn{2}{l}{ Blueberry $(\mathrm{CFU} / \mathrm{mL})$} \\
\cline { 2 - 5 } & yeast & mold & yeast & mold \\
\hline$\leq 6$ & none & none & none & none \\
7 & 7 & none & none & none \\
\hline
\end{tabular}




\begin{tabular}{lcccc}
\hline 8 & 13 & 1 & 1 & 1 \\
9 & 19 & 3 & 3 & 10 \\
10 & 2 & 8 & 8 & 1 \\
\hline
\end{tabular}

*: Each flavor had three trials and each trial of samples was performed in triplicate

Consumer acceptability: Table 7 summarizes the consumers' preference results for the plain yogurt samples. The data showed that commercial cows' milk yogurt presented higher preference values than water buffalo milk yogurt. Some of the positive descriptors of the cows' milk yogurt listed for the consumers that identified the product as being the favorite sample were: balanced, smooth, and not too sour. On the other hand, those consumers that selected the water buffalo milk yogurt as the less favorite sample justified their choice for the product being slightly bitter, grainy and with unpleasant aftertaste.

Table 7. Preference results for plain yogurt samples

\begin{tabular}{lll}
\hline Yogurt Source & $\begin{array}{l}\text { \% of consumers selected } \\
\text { product as “most favorite" }\end{array}$ & $\begin{array}{l}\text { \% of consumers selected } \\
\text { product as "least favorite" }\end{array}$ \\
\hline Commercial cows' milk & $\mathbf{3 3}$ & 24.7 \\
& & \\
\hline Water buffalo & 13.4 & $\mathbf{5 7 . 7}$ \\
\hline
\end{tabular}

No significant differences were found by gender, age, or yogurt eating habits associated with yogurt frequency intake. In terms of acceptability, the cows' milk yogurt significantly had higher scores for all the parameters evaluated than the water buffalo milk yogurt. As shown on Table 8, the higher score was associated with the texture of the cows' milk yogurt (5.990) while the lower score was for the flavor of water buffalo yogurt (4.786).

Table 8. Acceptability scores for plain yogurt samples

\begin{tabular}{lccc}
\hline Yogurt Source & Texture & Flavor & Overall \\
\hline Commercial cows' milk & $\mathbf{5 . 9 9 0}$ & $\mathbf{5 . 6 8 0}$ & $\mathbf{5 . 9 3 2}$ \\
\hline Water buffalo & 5.136 & 4.786 & 4.990 \\
\hline
\end{tabular}

Table 9 summarizes the consumers' preference results for the blueberry yogurts. The cows' milk yogurt presented the higher preference values than the water buffalo yogurt. Lack of flavor, high acidity and textural issues like chalkiness or graininess were the most frequent negative descriptors listed by consumers who disliked the water buffalo milk yogurt. Significant differences were found in terms of gender. Even though the cows' milk yogurt is the most preferred sample overall, more female consumers preferred water buffalo milk yogurt than male consumers. In terms of acceptability (Table 10), the cows' milk yogurt 
significantly scored higher values for all the parameters evaluated than the water buffalo milk yogurts.

Table 9. Preference results for blueberry yogurt samples

\begin{tabular}{lcc}
\hline Yogurt Source & $\begin{array}{l}\text { \% of consumers selected } \\
\text { product as "most favorite" }\end{array}$ & $\begin{array}{l}\text { \% of consumers selected } \\
\text { product as "least favorite" }\end{array}$ \\
\hline Commercial cows' milk & $\mathbf{5 8 . 7}$ & 10.8 \\
\hline Water buffalo & 19.6 & $\mathbf{5 0 . 5}$ \\
\hline
\end{tabular}

Table 10. Acceptability scores for blueberry yogurt samples

\begin{tabular}{llll}
\hline Yogurt Source & Color & Flavor & Overall \\
\hline Commercial cows' milk & $\mathbf{7 . 8 9 6}$ & $\mathbf{7 . 2 3 7}$ & $\mathbf{7 . 3 6 1}$ \\
\hline Water buffalo & 4.000 & 5.423 & 5.371 \\
\hline
\end{tabular}

\section{CONCLUSIONS:}

Data from this study shows variations in the gross composition and CLA content of water buffalo milk during the 12-month study. Water buffalo milk contains higher levels of total solids, crude protein, fat, calcium, and phosphorous and slightly higher content of lactose compared with those of cows' milk. The high level of total solids makes buffalo milk ideal for processing into value added dairy products such as cheese. The CLA content in milk ranged from $4.4 \mathrm{mg} / \mathrm{g}$ fat in September to $7.6 \mathrm{mg} / \mathrm{g}$ fat in June. Seasons and genetics may play a role in variation of CLA level and changes in gross composition of the water buffalo milk. The survivability of probiotics indicate that Bifidobacterium and L. casei survived in good numbers $\left(10^{7}\right.$ to $\left.10^{8} \mathrm{CFU} / \mathrm{g}\right)$ for both plain and blueberry yogurt throughout the storage period in the refrigeration condition. Further study should be focused on how to improve survivability of L. acidophilus in the low fat buffalo milk yogurt.

Authors Contributions: FL carried out the milk chemical composition analyses. XH participated in the design of the study was responsible for the microbial studies and drafted the manuscript. LZ helped in the statistical analysis. MG conceived of the study, and participated in its design and coordination and helped to draft the manuscript. All authors read and approved the final manuscript.

Acknowledgements: This study was supported in part by Woodstock Water Buffalo Company. Dr. Han was supported by the funds from the Development of Outstanding Young Teachers (HITQNJS.2008.055) during her visit in the US. 


\section{REFERENCES:}

1. Guo MR, Wang S, Li Z, Qu J, Jin L, Kindsted PS. Ethanol stability of goat's milk review 1968-1979. Int Dairy J 1998;8:57-60.

2. Nanda AS, Nakao T. Role of buffalo in the socioeconomic development of rural Asia: Current status and future prospectus. Animal Science Journal 2003;74:443-455.

3. Ligda D. The water buffalo., 1996.

4. Moio L, Dekimpe J, X. EP, Addeo F. The neutral volatile compounds of water buffalo milk. Pinerolo, ITALIE: Chiriotti, 1993.

5. Jayamanne VS, Adams MR. Survival of probiotic bifidobacteria in buffalo curd and their effect on sensory properties. Int J Food Sci Tech 2004;39:719-725.

6. Romano P, Ricciardi A, Salzano G, Suzzi G. Yeasts from Water Buffalo Mozzarella, a traditional cheese of the Mediterranean area. Int J Food Microbiol 2001;69:45-51.

7. Walstra P, Geurts T, Noomen A, Jellema A, Van Boekel M. Dairy Technology, principles of milk,properties and processes. New York: Marcel Dekker, 1999.

8. Khanal RC, Olson KC. Factors Affecting Conjugated Linoleic Acid (CLA) Content in Milk, Meat, and Egg: A Review. Asian Network for Scientific Information, Pakistan, 2004.

9. Kramer J, Parodi P, Jensen R, Mossoba M, Yurawecz M, Adlof R. Rumenic acid: A proposed common name for the major conjugated linoleic acid isomer found in natural products. Lipids 1998;33:835-835.

10. Ma DWL, Wierzbicki AA, Field CJ, Clandinin MT. Conjugated Linoleic Acid in Canadian Dairy and Beef Products. J Agric Food Chem 1999;47:1956-1960.

11. Griinari JM, Corl BA, Lacy SH, Chouinard PY, Nurmela KVV, Bauman DE. Conjugated Linoleic Acid Is Synthesized Endogenously in Lactating Dairy Cows by Delta9-Desaturase. The Journal of Nutrition 2000;130:2285-2291.

12. Ritzenthaler KL, McGuire MK, Falen R, Shultz TD, Dasgupta N, McGuire MA. Estimation of Conjugated Linoleic Acid Intake by Written Dietary Assessment Methodologies Underestimates Actual Intake Evaluated by Food Duplicate Methodology. The Journal of Nutrition 2001;131:1548-1554.

13. Belury MA. DIETARY CONJUGATED LINOLEIC ACID IN HEALTH: Physiological Effects and Mechanisms of Action1. Annu Rev Nutr 2002;22:505-531.

14. MacDonald HB. Conjugated Linoleic Acid and Disease Prevention: A Review of Current Knowledge. J Am Coll Nutr 2000;19:111S-118S.

15. Lin H, Boylston D, Chang MJ, Luedecke LO, Shultz TD. Survey of the Conjugated Linoleic Acid Contents of Dairy Products. J Dairy Sci 1995;78:2358-2365.

16. French P, Stanton C, Lawless F et al. Fatty acid composition, including conjugated linoleic acid, of intramuscular fat from steers offered grazed grass, grass silage, or concentrate-based diets. J Anim Sci 2000;78:2849-2855.

17. Dhiman TR, Anand GR, Satter LD, Pariza MW. Conjugated Linoleic Acid Content of Milk from Cows Fed Different Diets. J Dairy Sci 1999;82:2146-2156.

18. Samona A, Robinson RK, Marakis S. Acid production by bifidobacteria and yogurt 
bacteria during fermentation and storage of milk. Food Microbiol 1996;13:275-280.

19. Shah NP. Functional cultures and health benefits. Int Dairy J 2007;17:1262-1277.

20. Gün Ö, Isikli ND. Effect of fat and non-fat dry matter of milk, and starter type, on the rheological properties of set during the coagulation process. International Journal of Food Science and Technology 2007;42:352-358.

21. Kailasapathy K, Harmstorf I, Phillips M. Survival of Lactobacillus acidophilus and Bifidobacterium animalis ssp. lactis in stirred fruit yogurts. LWT - Food Science and Technology 2008;41:1317-1322.

22. IDF. International Standard 163. General standard of identity for fermented milks. Brussels: International Dairy Federation, 1992.

23. Dave RI, Shah NP. Viability of yogurt and probiotic bacteria in yogurts made from commercial starter cultures. International Dairy Journal 1997;7:31-41.

24. Grosso CRF, Fávaro-Trindade CS. Stability of free and immobilized Lactobacillus acidophilus and Bifidobacterium lactis in acidified milk and of immobilized B. lactis in yogurt. Brazilian Journal of Microbiology 2004;35:151-156.

25. Mattila-Sandholm T, Myllärinen P, Crittenden R, Mogensen G, Fondén R, Saarela M. Technological challenges for future probiotic foods. International Dairy Journal 2002;12:173-182.

26. Ongol MP, Sawatari Y, Ebina Y et al. Yogurt fermented by Lactobacillus delbrueckii subsp. bulgaricus H+-ATPase-defective mutants exhibits enhanced viability of Bifidobacterium breve during storage. Int J Food Microbiol 2007;116:358-366.

27. Lourens-Hattingh A, Viljoen BC. Yogurt as probiotic carrier food. International Dairy Journal 2001;11:1-17.

28. Oliveira RPDS, Perego P, Converti A, Oliveira MND. Effect of inulin on growth and acidification performance of different probiotic bacteria in co-cultures and mixed culture with Streptococcus thermophilus. J Food Eng 2009;91:133-139.

29. Laroia S, Martin JH. Effect of $\mathrm{pH}$ on survival of Bifidobacterium bifidum and Lactobacillus acidophilus in frozen fermented dairy desserts. Cultured Dairy Products Journal 1991;26.

30. Dave RI, Shah NP. Ingredient supplementation effects on viability of probiotic bacteria in yogurt. Journal of dairy science 1998;81:2804-16.

31. Bradley RL. Dairy foods. In: Horwitz W, editor Official Methods of Analysis of the AOAC International. 17th ed. Gaithersburg: AOAC International, 2002:1-88.

32. Christie W. Composition and structure of milk lipids. In: Fox PF, editor Advanced Dairy Chemistry. 2nd ed. London: Chapman \& Hall, 1995:136.

33. Bradley RL, Arnold E, Barbano DM, Semerad RG, Smith DE, Vines BK. Chemical and physical methods. In: Marshall RT, editor Standard Methods for the Examination of Dairy Products. 16 ed. Washington D.C.: American Public Health Association, 1992:433-531.

34. Christie WW. A simple procedure for rapid transmethylation of glycerolipids and cholesteryl esters. J Lipid Res 1982;23:1072-5. 
35. Shahin A, McGuire M, McGuire M, Ritzenthaler K, Shultz T. Determination of c9,t11-CLA in major human plasma lipid classes using a combination of methylating methodologies. Lipids 2003;38:793-800.

36. Hooi R, Barbano DM, Bradley RL et al. Standard Methods. In: Wehr MH, Frank JF, editors. Standard Methods for the Examination of Dairy Products. 17 ed. Washington DC: American Public Health Association, 2004:408-451.

37. Delwiche S. Cereal foods. In: Horwitz W, editor Official methods of analysis of the AOAC. 17th ed. Gaithersburg: AOAC Intl. , 2002:1-58.

38. Guo MR, Dixon PH, Park YW, Gilmore JA, Kindstedt PS. Seasonal Changes in the Chemical Composition of Commingled Goat Milk. J Dairy Sci 2001;84, Supplement:E79-E83.

39. Gokavi S, Zhang L, Huang M-K, Zhao X, Guo M. Oat-based Symbiotic Beverage Fermented by Lactobacillus plantarum, Lactobacillus paracasei ssp. casei, and Lactobacillus acidophilus. Journal of Food Science 2005;70:M216-M223.

40. ISO. 20128:2006 (IDF 192: 2006) Milk products - Enumeration of presumptive Lactobacillus acidophilus on selective medium - Colony count technique at $37^{\circ} \mathrm{C}$.: IDF, 2006:11.

41. Barłowska J, Szwajkowska M, Litwińczuk Z, Król J. Nutritional Value and Technological Suitability of Milk from Various Animal Species Used for Dairy Production. Comprehensive Reviews in Food Science and Food Safety 2011;10:291302.

42. Bergamo P, Fedele E, Iannibelli L, Marzillo G. Fat-soluble vitamin contents and fatty acid composition in organic and conventional Italian dairy products. Food Chem 2003;82:625-631.

43. Lal D, M NK. Effect of lactation number on the polyunsaturated fatty acids and oxidation stability of milk fats. Indian Journal of Dairy Science 1984:225-229.

44. Parodi PW. Conjugated Octadecadienoic Acids of Milk Fat. J Dairy Sci 1977;60:1550-1553.

45. Fundora O, González ME, Lezcano O, Montejo A, Pompa N, Enriquez AV. A comparative study of milk composition and stability of Murrah river buffaloes and Holstein cows grazing star grass. Cuban Journal of Agricultural Science 2001;35:219222.

46. Lindmark-Månsson H, Fondén R, Pettersson H-E. Composition of Swedish dairy milk. Int Dairy J 2003;13:409-425.

47. Yun YE. Study on Chemical and Microbiological Compositions and Identification of Lactic acid bacteria from Natural Fermented Goat milk in Qinghai. . Inner Mongolia Agriculture University: Huhhot, China, 2006:124.

48. Shah NP. Probiotic bacteria: selective enumeration and survival in dairy foods. Journal of dairy science 2000;83:894-907.

49. Kailasapathy K. Survival of free and encapsulated probiotic bacteria and their effect on the sensory properties of yogurt. LWT - Food Science and Technology 
2006;39:1221-1227.

50. Shah NP, Lankaputhra WEV, Britz ML, Kyle WSA. Survival of Lactobacillus acidophilus and Bifidobacterium bifidum in commercial yogurt during refrigerated storage. International Dairy Journal 1995;5:515-521.

51. Olson DW, Aryana KJ. An excessively high Lactobacillus acidophilus inoculation level in yogurt lowers product quality during storage. LWT - Food Science and Technology 2008;41:911-918. 